Open Access

\title{
Diagnostic value of decoy receptor 3 combined with procalcitonin and soluble urokinase-type plasminogen activator receptor for sepsis
}

\author{
Jing-jing Zhao ${ }^{\dagger}$, Xiao-Li Lou ${ }^{\dagger}$, Hong-wei Chen, Feng-ting Zhu and Yan-Qiang Hou ${ }^{*}$
}

* Correspondence:

houyanqiang@aliyun.com

†Equal contributors

Department of Central Laboratory,

Songjiang Hospital Affiliated First

People's Hospital, Shanghai Jiao

Tong University, Shanghai 201600, China

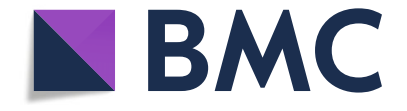

\section{Introduction}

Sepsis is a systemic inflammatory response syndrome (SIRS) caused by infection that eventually leads to organ dysfunction and death. SIRS is the leading cause of death in intensive care unit (ICU) patients. According to the global estimates, there are 31.5 million sepsis and 19.4 million severe sepsis cases, with potentially 5.3 million deaths annually. The mortality rate of sepsis decreases year by year, but the number of patients who die from sepsis is increasing with increasing morbidity $[1,2]$. The identification of causative pathogens through blood cultures is still the gold standard of sepsis diagnosis. However, confirmation of pathogens by cultures is slow and it often yields false negative results [3]. The problem of effectively treating patients with sepsis is in part attributed to the difficulty of accurately diagnosing sepsis especially in its early

(c) The Author(s). 2018 Open Access This article is distributed under the terms of the Creative Commons Attribution 4.0 International License (http://creativecommons.org/licenses/by/4.0/), which permits unrestricted use, distribution, and reproduction in any medium, provided you give appropriate credit to the original author(s) and the source, provide a link to the Creative Commons license, and indicate if changes were made. The Creative Commons Public Domain Dedication waiver (http://creativecommons.org/ publicdomain/zero/1.0/) applies to the data made available in this article, unless otherwise stated.

Keywords: Sepsis, SIRS, DCR3, suPAR, PCT 
stages. Therefore, better and faster biological indicators in the early diagnosis of sepsis are sought.

Decoy receptor 3 (DcR3) is a new member of the tumor necrosis factor receptors superfamily, which competitively binds Fas ligand, LIGHT and TL1A to block apoptosis. Previous studies have suggested that DcR3 expression is upregulated in inflammatory diseases, such as bacterial infections, rheumatoid arthritis, acute ulcerative colitis, appendicitis, and cancers, and primarily functions to prevent inflammation and apoptosis $[4,5]$. Our preliminary study showed that DcR3 expression has diagnostic value for sepsis [6], and is a valuable marker to predict the outcome of sepsis [7].

Currently, procalcitonin (PCT) and soluble urokinase type plasminogen activator receptor (suPAR) are used as laboratory diagnostic indicators of sepsis. While these tests have a wide range of clinical applications, better tests would be helpful for patients [8-11]. This study aimed to explore the value of measuring DcR3 combined with suPAR and PCT expression in the clinical diagnosis of sepsis.

\section{Materials and methods}

\section{Study subjects}

Thirty-four patients with sepsis, who were hospitalized in the intensive care unit of our hospital in Songjiang District Center Hospital, Shanghai, China, from August 2015 to December 2016, were recruited. Meanwhile, 34 patients with SIRS and 20 healthy subjects who had not recently suffered from infection or autoimmune disease and with normal results obtained by physical examination were recruited as healthy controls.

Inclusion criteria: age $\geq 18$ years, sepsis diagnosis conforms to the standard of the Surviving Sepsis Campaign: International Guidelines for Management of Severe Sepsis and Septic Shock [12]. Patients whose SIRS diagnosis conformed to the standard of the 1991 ACCP/SCCM were also recruited [13].

Exclusion criteria: (1) HIV infection, confirmed rheumatoid arthritis, white blood cell (WBC) count $<1 \times 10^{9} / \mathrm{L}$ or neutrophil cells count $<0.5 \times 10^{9} / \mathrm{L}$; (2) onset of acute myocardial infarction, cerebral infarction or hemorrhage in the past 6 months; (3) comorbidity of severe liver, kidney malfunction, heart failure, blood disease, malignant tumor, and psychiatric patients; (4) use of glucocorticoids equal to a dosage of $1 \mathrm{mg} / \mathrm{kg}$ of prednisone for $>1$ month, use of immunosuppressive drugs, or death within $24 \mathrm{~h}$ of enrollment in the intensive care unit.

\section{Collection of blood samples and measurement of indicators}

Venous blood samples $(2 \mathrm{~mL})$ were immediately collected from sepsis and SIRS patients before treatment when they were admitted to the hospital. Blood was harvested in test tubes with coagulant and subjected to mixing and centrifugation at $3500 \mathrm{rpm}$ for $15 \mathrm{~min}$ at $4{ }^{\circ} \mathrm{C}$. Serum was immediately separated, transferred into frozen tubes and stored at $-80{ }^{\circ} \mathrm{C}$. Serum of the control group was collected in the same way. Serum DcR3 (RayBio, Norcross, GA, USA) and serum suPAR (ViroGates, Birkerod, Denmark) levels were detected by an human enzyme-linked immunosorbent assay (ELISA) kit using an iMark Microplate reader (Bio-Rad, Hercules, CA, USA); interleukin-6 (IL-6) and PCT levels were determined using electrochemical luminescence with a Cobas e601 instrument (Roche, Basle, Switzerland). 


\section{Statistical methods}

SPSS version 19.0 (SPSS Inc., Chicago, IL, USA) software was employed to carry out the statistical analysis. The Mann-Whitney $U$ test was used to compare continuous parametric variables. One-way analysis of variance or the Kruskal-Wallis test was used to compare more than two groups of quantitative data. A 2-sided $P<0.05$ was considered significant. Spearman's rank correlation analysis was used to determine bi-variant relationships. Receiver operating characteristics (ROC) curves were constructed and the area under the curve (AUC) was calculated. Significant indexes were combined as joint diagnostic indexes. Logistic regression analysis was used to construct combined predictors. All data are presented as mean \pm standard error or median (minimum-maximum).

\section{Results}

\section{General information and clinical data of the patients}

We found that there was no statistically significant difference $(P>0.05)$ in age and sex among the sepsis group $(n=34)$, SIRS group $(n=34)$ and control group $(n=20)$. The IL-6, WBC and C-reactive protein (CRP) levels of the sepsis group and SIRS group were significantly higher than those of the control group $(P<0.05)$. However, there was no significant difference between the SIRS group and sepsis group (Table 1).

\section{Change of serum DcR3, suPAR and PCT levels in patients with sepsis}

The serum DcR3 level of the sepsis group [4.65 $(0.38,27.62) \mathrm{ng} / \mathrm{mL}]$ was significantly higher than that of the SIRS group $[0.58(0.00,8.72) \mathrm{ng} / \mathrm{mL}]$ and control group $[0.16(0.00,0.73 \mathrm{ng} / \mathrm{mL}]$ (both $P<0.001$; Fig. 1a). The serum suPAR level of the sepsis group $(12.78 \pm 5.19 \mathrm{ng} / \mathrm{mL})$ was also significantly higher than that of the SIRS group $(7.67 \pm 5.56 \mathrm{ng} / \mathrm{mL})$ and control group $(2.93 \pm 1.14 \mathrm{ng} / \mathrm{mL}) \quad(P<0.001$; Fig. 1b). The serum PCT level of the sepsis group $[6.58(0.13,30.25) \mathrm{ng} / \mathrm{mL}]$ was significantly higher than that of the SIRS $[1.39(0.03,20.28) \mathrm{ng} / \mathrm{mL}](P<0.001)$ and control group $[0.065(0.02,0.75) \mathrm{ng} / \mathrm{mL}](P<0.05$; Fig. $1 \mathrm{c})$.

\section{Correlation of DcR3 levels with other indicators}

To determine the correlation between DcR3 levels and other indicators, the indexes of the sepsis group were subjected to correlation analysis. Serum DcR3 was positively correlated with PCT and suPAR (Fig. 2).

Table 1 Clinical data of patients and healthy controls

\begin{tabular}{llll}
\hline & Control $(n=20)$ & $\operatorname{SIRS}(n=34)$ & Sepsis $(n=34)$ \\
\hline Age & $63.20 \pm 8.82$ & $57.06 \pm 21.91$ & $67.50 \pm 12.59$ \\
Gender $(\mathrm{M} / \mathrm{F})$ & $14 / 6$ & $20 / 14$ & $20 / 14$ \\
IL-6 $(\mathrm{pg} / \mathrm{mL})$ & $6.63(3.42-23.39)$ & $77.41(3.31-1971.00)^{* *}$ & $100.65(8.41-5900.00)^{* *}$ \\
WBC $\left(\times 10^{9} / \mathrm{L}\right)$ & $6.87 \pm 1.62$ & $16.62 \pm 4.58^{* *}$ & $18.40 \pm 3.52^{* *}$ \\
CRP $(\mathrm{mg} / \mathrm{L})$ & $4.00(1.00-33.00)$ & $37.50(1.00-177.00)^{* *}$ & $51.00(0.49-325.00)^{* *}$ \\
\hline
\end{tabular}




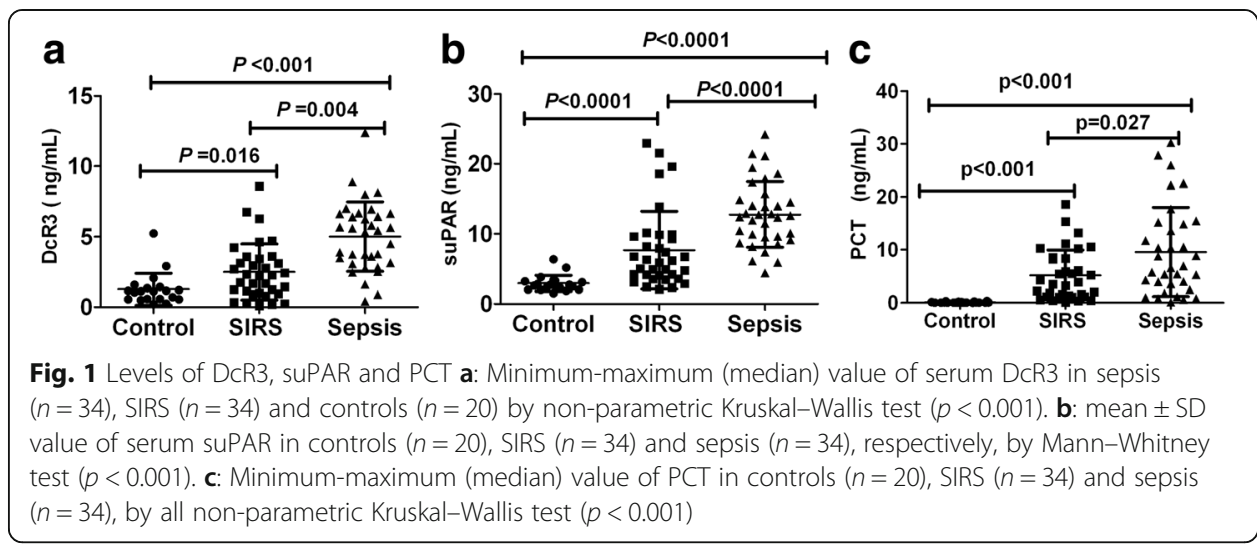

\section{Diagnostic value of single indicator and combination for distinguishing control group} from SIRS

The predictive values of the indicators for SIRS were determined and compared. Compared with the control group, the AUC values of DcR3, suPAR, and PCT were 0.768, 0. 876 and 0.858 , respectively (Fig. 3). The sensitivity and specificity of suPAR and PCT for SIRS were higher than those of DcR3. The AUC values of the combinations of DcR3 + suPAR, DcR3 + PCT, suPAR+PCT, DcR3 + suPAR+PCT were 0.893, 0.875, 0. 946 and 0.947 ; the sensitivity values were 85.3, 79.4, 97.1 and $94.1 \%$; the specificity values were 85.0, 85.0, 80.0 and $80.0 \%$, respectively. It suggested that the co-detection of DcR3 + suPAR+PCT for SIRS did not improve the diagnostic efficiency (Table 2).

Diagnostic value of single indicator and combination for distinguishing control group from sepsis

DcR3, suPAR and PCT were evaluated by ROC curve analysis for the control group vs. the sepsis group (Fig. 4), with the AUC determined to be 0.990, 0.938 and 0.972, respectively. The AUC of DcR3 was found to be greater than that of suPAR and PCT, suggesting that DcR3 was better than suPAR and PCT in the diagnosis of sepsis. The AUC of DcR3 + suPAR+PCT is 0.997, which is better than DcR3 + suPAR (AUC =0.996) or DcR3 + PCT $($ AUC $=0.990)$ or suPAR+PCT $(A U C=0.969)$, and DcR3 + suPAR+PCT has the best specificity, indicating that the combination of the three indexes had the best diagnostic performance in sepsis (Table 3).
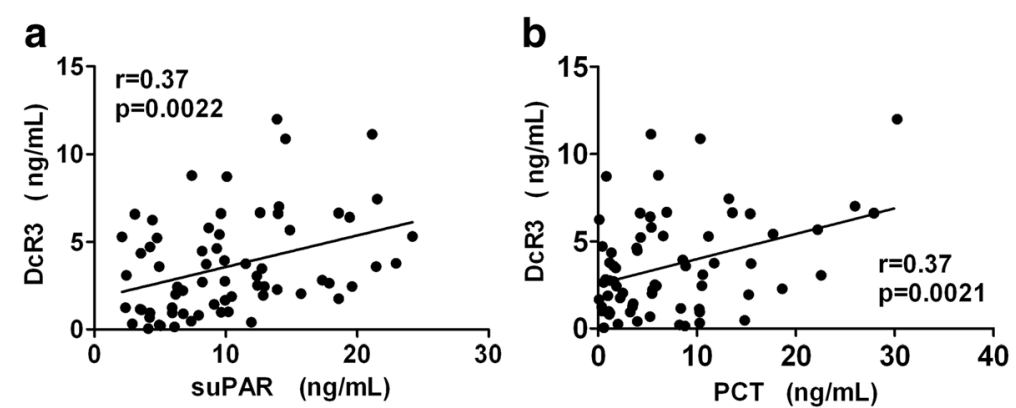

Fig. 2 Correlation between DCR3 and PCT (a, $r=0.37, p=0.0021)$, DCR3 and suPAR $(\mathbf{b}, r=0.37$, $p=0.0022$ ), respectively 


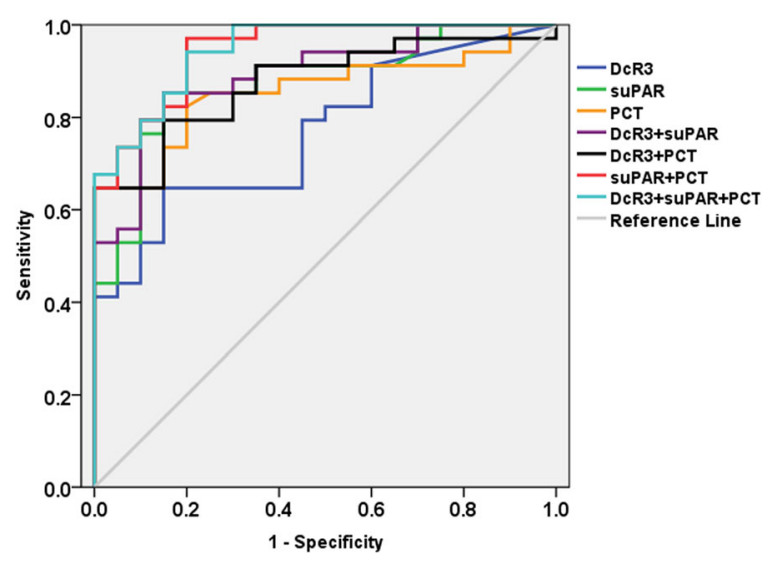

Fig. 3 ROC evaluation of DCR3, sUPAR, PCT and DCR3 combined with suPAR, PCT in control group vs. SIRS group. The ROC evaluation was performed at cut-off values recommended by the scientific community of laboratory medicine with $95 \% \mathrm{Cl}$

Diagnostic value of single indicator and combination for distinguishing SIRS from sepsis In order to further clarify the diagnostic value, DcR3, suPAR and PCT were used to distinguish SIRS from sepsis. Compared with the SIRS group, the AUC of DcR3 was the best predictor for sepsis (0.892 vs. 0.778 (suPAR) vs. 0.692 (PCT), respectively). When the DcR3 level was $1.690 \mathrm{ng} / \mathrm{mL}$, the sensitivity and specificity were 91.2 and 82 . $4 \%$, indicating that DcR3 has potential application value in the diagnosis of sepsis. The AUC of DcR3 + suPAR+PCT combined was 0.933, higher than for DcR3 + SuPAR $(A U C=0.897)$ or DcR3 + PCT $(A U C=0.916)$ or suPAR+PCT $(A U C=0.779)$. When the cut-off of DcR3 + suPAR+PCT was 0.342 , the sensitivity and specificity were 94.1 and 91.2\%. (Fig. 5) Thus, the combination of the three indexes enhanced the accuracy and prediction efficiency, compared to a single index (Table 4).

\section{Discussion}

Sepsis is a rapidly propagating excessive inflammatory reaction that occurs in response to a variety of pathogenic bacteria entering the blood system, producing a large number of toxins. The laboratory indicators used for the clinical diagnosis of sepsis include CRP, IL-6, IL-8, tumor necrosis factor- $\alpha$ (TNF- $\alpha$ ) and PCT, none of which are ideal diagnostic indicators due to their deficiencies in diagnostic specificity and sensitivity [14-17]. For many years, researchers have carried

Table 2 Receiver operating characteristic analysis of DCR3, sUPAR and PCT in control and SIRS

\begin{tabular}{|c|c|c|c|c|c|c|c|c|}
\hline & \multirow[t]{2}{*}{ AUC } & \multirow{2}{*}{$\begin{array}{l}\text { SID } \\
\text { error }\end{array}$} & \multirow[t]{2}{*}{ Sig } & \multicolumn{2}{|l|}{$95 \% \mathrm{Cl}$} & \multirow{2}{*}{$\begin{array}{l}\text { Cut-off } \\
\text { value }\end{array}$} & \multirow[t]{2}{*}{ Sensitivity } & \multirow[t]{2}{*}{ Specificity } \\
\hline & & & & Lower limit & Upper limit & & & \\
\hline DcR3 & 0.768 & 0.063 & 0.001 & 0.643 & 0.892 & $0.190 \mathrm{ng} / \mathrm{mL}$ & 0.79 .4 & 0.550 \\
\hline SUPAR & 0.876 & 0.048 & 0.000 & 0.781 & 0.970 & $0.519 \mathrm{ng} / \mathrm{mL}$ & 0.85 .3 & 0.850 \\
\hline PCT & 0.858 & 0.051 & 0.000 & 0.758 & 0.958 & $0.375 \mathrm{ng} / \mathrm{mL}$ & 0.824 & 0.800 \\
\hline$D c R 3+$ suPAR & 0.893 & 0.044 & 0.000 & 0.807 & 0.978 & 0.440 & 0.853 & 0.850 \\
\hline $\mathrm{DcR} 3+\mathrm{PCT}$ & 0.875 & 0.047 & 0.000 & 0.783 & 0.967 & 0.517 & 0.794 & 0.850 \\
\hline SUPAR+PCT & 0.946 & 0.029 & 0.000 & 0.890 & 1.000 & 0.308 & 0.971 & 0.800 \\
\hline DcR3 + suPAR+PCT & 0.947 & 0.028 & 0.000 & 0.893 & 1.000 & 0.310 & 0.941 & 0.800 \\
\hline
\end{tabular}




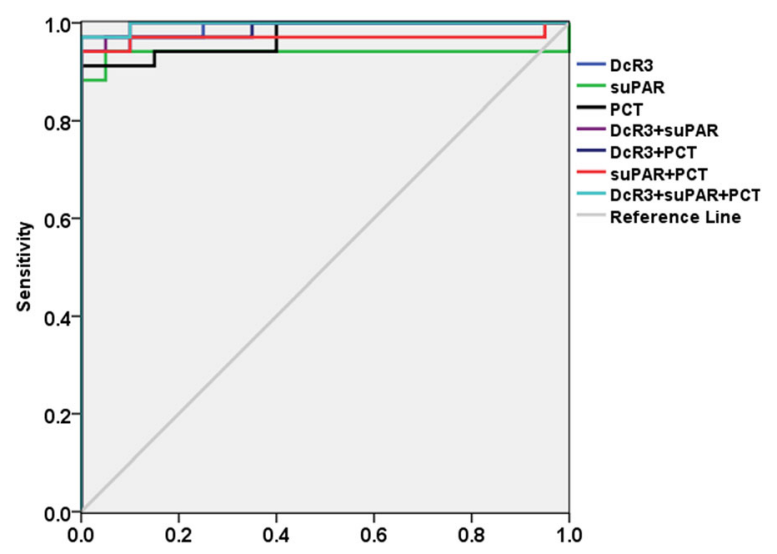

Fig. $4 R O C$ evaluation of DCR3, sUPAR, PCT and DcR3 combined with suPAR, PCT in control group vs. sepsis group. The ROC evaluation was performed at cut-off values recommended by the scientific community of laboratory medicine with $95 \% \mathrm{Cl}$

out a large number of studies and clinical trials, but the pathogenesis of sepsis is still not fully elucidated, which also hampers effective treatment, resulting in high mortality $[18,19]$. Therefore, it is important to find a new diagnostic indicator to improve the treatment of sepsis and reduce mortality.

Currently, PCT is considered to be the best laboratory diagnostic indicator of sepsis, but its value for diagnosis, prognosis and the differential diagnosis with SIRS is not satisfactory [20-22]. A meta-analysis showed that the sensitivity and specificity of PCT in early sepsis diagnosis in critically ill patients were $77 \%$ (95\% CI: $72-81 \%$ ) and 79\% (95\% CI: 74-84\%). However, since PCT levels can rise due to surgery as well as inflammatory and autoimmune diseases, its specificity in sepsis diagnosis is limited [23]. Pierrakos et al. [24] analyzed 178 diagnostic indicators of sepsis in 3370 papers, concluding that PCT is deficient for diagnosis, differential diagnosis and prognosis of sepsis. In this study, the AUC, sensitivity and specificity of PCT were determined to be $0.692,79.4$ and $55.9 \%$, respectively, which also indicated that the diagnostic specificity of PCT was low in sepsis diagnosis. Therefore, it is urgent to find new indicators for the diagnosis and prognosis of sepsis.

SUPAR is the soluble form of urokinase type plasminogen activator receptor (uPAR). Under inflammatory stimulation, uPAR is removed from the cell surface

Table 3 Receiver operating characteristic analysis of DcR3, suPAR and PCT in control and sepsis

\begin{tabular}{|c|c|c|c|c|c|c|c|c|}
\hline & \multirow[t]{2}{*}{ AUC } & \multirow{2}{*}{$\begin{array}{l}\text { SID } \\
\text { error }\end{array}$} & \multirow[t]{2}{*}{ Sig } & \multicolumn{2}{|l|}{$95 \% \mathrm{Cl}$} & \multirow{2}{*}{$\begin{array}{l}\text { Cut-off } \\
\text { value }\end{array}$} & \multirow[t]{2}{*}{ Sensitivity } & \multirow[t]{2}{*}{ Specificity } \\
\hline & & & & Lower limit & Upper limit & & & \\
\hline$\overline{D c R 3}$ & 0.990 & 0.009 & 0.000 & 0.971 & 1.000 & $0.545 \mathrm{ng} / \mathrm{mL}$ & 0.971 & 0.900 \\
\hline SUPAR & 0.938 & 0.040 & 0.000 & 0.859 & 1.000 & $5.535 \mathrm{ng} / \mathrm{mL}$ & 0.941 & 0.850 \\
\hline PCT & 0.972 & 0.019 & 0.000 & 0.935 & 1.000 & $0.513 \mathrm{ng} / \mathrm{mL}$ & 0.941 & 0.870 \\
\hline DcR3 + suPAR & 0.996 & 0.005 & 0.000 & 0.986 & 1.000 & 0.489 & 0.971 & 0.950 \\
\hline $\mathrm{DcR} 3+\mathrm{PCT}$ & 0.990 & 0.011 & 0.000 & 0.968 & 1.000 & 0.237 & 0.971 & 0.950 \\
\hline SUPAR + PCT & 0.969 & 0.028 & 0.000 & 0.915 & 1.000 & 0.297 & 0.971 & 0.900 \\
\hline DcR3 + suPAR + PCT & 0.997 & 0.004 & 0.000 & 0.989 & 1.000 & 0.345 & 0.971 & 0.980 \\
\hline
\end{tabular}




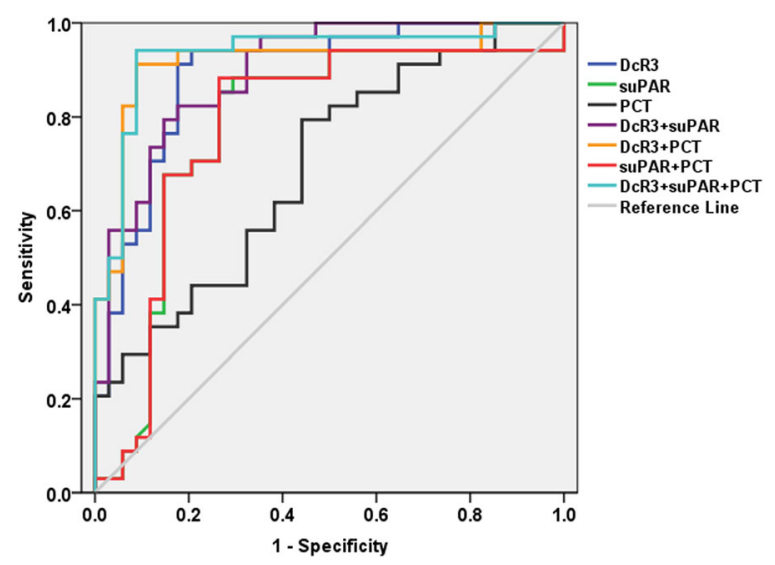

Fig. 5 ROC evaluation of DcR3, sUPAR, PCT and DcR3 combined with suPAR, PCT in SIRS group vs. sepsis group. The ROC evaluation was performed at cut-off values recommended by the scientific community of laboratory medicine with $95 \% \mathrm{Cl}$

through the activity of a variety of proteases, forming suPAR [25]. Increased suPAR levels, which were believed to be a good biomarker for sepsis diagnosis, primarily occur in patients with cancer and a variety of infectious and inflammatory diseases [26]. Recent studies have shown that suPAR levels are significantly increased in sepsis and could reflect the severity of sepsis [27-29]. In vivo studies have found that stimulation by high dose endotoxin can increase suPAR levels, while low dose endotoxin stimulation failed to increase suPAR levels [30]. This study found that suPAR levels were significantly increased in sepsis patients. When compared with the control group, at a cut-off point of $5.535 \mathrm{ng} / \mathrm{mL}$, the sensitivity and specificity for diagnosis of sepsis using suPAR were 94.1 and $85.0 \%$, and the PCT was comparable, while the area under the ROC curve was smaller than the PCT, similar to the results of the study published by Zeng [31]. When distinguishing SIRS from sepsis using suPAR, the optimal cut-off point was $8.355 \mathrm{ng} / \mathrm{mL}$. At this point, the sensitivity and specificity were 85.3 and $73.5 \%$, respectively, which was better than PCT, indicating that suPAR had a better sensitivity in sepsis diagnosis.

DcR3 is a member of the soluble tumor necrosis factor receptor superfamily lacking transmembrane structures. Some studies have shown that DcR3 can reduce inflammatory responses by promoting the secretion of anti-inflammatory factors and down-

Table 4 Receiver operating characteristic analysis of DCR3, sUPAR and PCT in SIRS and sepsis

\begin{tabular}{|c|c|c|c|c|c|c|c|c|}
\hline & \multirow[t]{2}{*}{ AUC } & \multirow{2}{*}{$\begin{array}{l}\text { SID } \\
\text { error }\end{array}$} & \multirow[t]{2}{*}{ Sig } & \multicolumn{2}{|l|}{$95 \% \mathrm{Cl}$} & \multirow{2}{*}{$\begin{array}{l}\text { Cut-off } \\
\text { value }\end{array}$} & \multirow[t]{2}{*}{ Sensitivity } & \multirow[t]{2}{*}{ Specificity } \\
\hline & & & & Lower limit & Upper limit & & & \\
\hline$\overline{D c R 3}$ & 0.892 & 0.040 & 0.000 & 0.813 & 0.971 & $1.690 \mathrm{ng} / \mathrm{mL}$ & 0.912 & 0.824 \\
\hline SUPAR & 0.778 & 0.062 & 0.000 & 0.657 & 0.900 & $8.355 \mathrm{ng} / \mathrm{mL}$ & 0.853 & 0.735 \\
\hline PCT & 0.692 & 0.064 & 0.006 & 0.568 & 0.817 & $2.255 \mathrm{ng} / \mathrm{mL}$ & 0.794 & 0.559 \\
\hline DcR3 + suPAR & 0.897 & 0.037 & 0.000 & 0.824 & 0.970 & 0.374 & 0.824 & 0.824 \\
\hline $\mathrm{DcR} 3+\mathrm{PCT}$ & 0.916 & 0.039 & 0.000 & 0.840 & 0.993 & 0.356 & 0.912 & 0.912 \\
\hline SUPAR + PCT & 0.779 & 0.062 & 0.000 & 0.658 & 0.901 & 0.427 & 0.882 & 0.735 \\
\hline $\mathrm{DcR} 3+\mathrm{suPAR}+\mathrm{PCT}$ & 0.933 & 0.034 & 0.000 & 0.867 & 0.998 & 0.342 & 0.941 & 0.912 \\
\hline
\end{tabular}


regulating the expression of inflammatory factors [32, 33]. Our previous study established a mouse model of sepsis and applied dose-dependent DcR3 treatment. It showed that DcR3 significantly inhibited the inflammatory reaction, and reduced lymphocyte apoptosis in the thymus and spleen, improving survival rates [34]. DcR3 can modulate macrophage differentiation and the secretion of inflammatory cytokines and chemokines, functioning as part of the immune surveillance and immune regulation systems, indicating that DcR3 may play a role in the early pathological mechanisms of sepsis [35]. In this study, we found that the DcR3 level was significantly increased in sepsis patients. Furthermore, on evaluation of the ROC curve, our findings showed that when the DcR3 cut-off point was $1.690 \mathrm{ng} / \mathrm{mL}$, the sensitivity and specificity of DcR3 were 91.2 and $82.4 \%$, which was better than those of suPAR and PCT to distinguish SIRS from sepsis, indicating that DcR3 shows great promise for use as a diagnostic biomarker of sepsis. Gao et al. [36] found that DcR3 increased significantly in the early stage of sepsis and monitoring its outcome, especially when sepsis patients were PCT negative. However, DcR3 levels showed no difference among various pathogens associated with sepsis.

Although the above three biological indicators have certain application value in the early diagnosis of sepsis, they are limited by various conditions and cannot be used independently as an ideal indicator for diagnosis of sepsis. Therefore, in order to improve the early diagnosis of sepsis, we also evaluated the diagnostic value of combined examination of DcR3, suPAR and PCT by the ROC curve. Our results suggested that the effect of a single indicator in the diagnosis of sepsis is not ideal, and diagnosis using multiple indicators in combination may be more effective [24]. Compared with the control group, the sensitivity and specificity of DcR3 + suPAR+PCT for sepsis were 97.1 and $98.0 \%$, which were superior to those of suPAR+PCT or DcR3 + suPAR or DcR3 + PCT. DcR3, suPAR and PCT were used to distinguish SIRS from sepsis; when the optimal cut-off point of DcR3 + suPAR + PCT was 0.342 , the sensitivity and specificity were 94.1 and $91.2 \%$, showing that this combination enhanced the accuracy and prediction efficiency, compared to a single index. Moreover, in this study a correlation analysis was carried out among DcR3, suPAR and PCT, which showed that DcR3 was correlated with suPAR and PCT, suggesting that use of the combination of the three indexes has a higher clinical diagnostic value for sepsis.

In summary, the host response to sepsis involves hundreds of mediators and single molecules, many of which have been proposed to be sepsis biomarkers. It is unlikely that is able to satisfy all the existing needs and expectations in sepsis research and management. The combined diagnostic value of the three indicators is higher than that of the single indicator. However, the number of samples in this study was small, and further large-scale clinical studies are needed to verify the results, and to provide new ideas for the pathogenesis of sepsis and early treatment.

Abbreviations

ACCP/SCCM: American College of Clinical Pharmacy/Society of Critical Care Medicine; HIV: Human immunodeficiency virus; LIGHT: A receptor expressed by T lymphocytes; TL1A: TNF-like ligand 1A 


\section{Funding}

The study described in the manuscript was supported by the Scientific Foundation of Shanghai Municipal Commission of Health and Family Planning (No. 201540119 and No. 20164Y0273) and the Science and Technology Research Project of Songjiang District of Shanghai (No. 15SJGG25 and No. 15SJGG47).

\section{Availability of data and materials}

The datasets supporting the conclusion of this article are included in the article.

\section{Authors' contributions}

YH conceived the idea and designed the study. YH and JZ contributed to the data analysis and writing of the manuscript. XL helped to conduct the experiments and data analysis. HC and FZ collected clinical blood specimens and clinical data. HC performed indicator assays. All authors read and approved the final manuscript.

\section{Ethics approval and consent to participate}

This manuscript does not report on studies involving human tissue and animal data. The human data reported in this manuscript were collected according to the approved procedures under the Institutional Ethical Review Boards of Songjiang District Center Hospital.

\section{Competing interests}

The authors declare that they have no competing interests.

\section{Publisher's Note}

Springer Nature remains neutral with regard to jurisdictional claims in published maps and institutional affiliations.

\section{Received: 5 January 2018 Accepted: 25 April 2018}

Published online: 09 May 2018

\section{References}

1. Fleischmann C, Scherag A, Adhikari NK, et al. Assessment of global incidence and mortality of hospital-treated sepsis. Current estimates and limitations. AJRCCM. 2016;193:259-72.

2. Lagu T, Rothberg MB, Shieh MS, et al. Hospitalizations, costs and outcomes of severe sepsis in the United States 2003 to 2007. Crit Care Med. 2012;40:754-61.

3. Klouche M, Schröder U. Rapid methods for diagnosis of bloodstream infections. Clin Chem Lab Med. 2008:46:888-908.

4. Hsieh SL, Lin WW. Decoy receptor 3: an endogenous immunomodulator in cancer growth and inflammatory reactions. J Biomed Sci. 2017;24:39-47.

5. Kim S, Fotiadu A, Kotoula V. Increased expression of soluble decoy receptor 3 inacutely inflamed intestinal epithelia. Clin Immunol. 2005;115:286-94.

6. Hou YQ, Xu P, Zhang M, et al. Serum decoy 3, a potential new biomarker for sepsis. Clin Chim Acta. 2012;413:744-8.

7. Kim S, Mi L, Zhang L. Specific elevation of DCR3 in sera of sepsis patients and its potential role as a clinically important biomarker of sepsis. Diagn Microbiol Infect Dis. 2012;73:312-7.

8. Hu C, Zhou Y, Liu C, et al. Pentraxin-3, procalcitonin and lactate as prognostic markers in patients with sepsis and septic shock. Oncotarget. 2017;9:5125-36.

9. Donadello K, Scolletta S, Covajes C. suPAR as a prognostic biomarker in sepsis. BMC Med. 2012;10:2.

10. Henriquez-Camacho C, Losa J. Biomarkers for sepsis. Biomed Res Int. 2014;2014:547818.

11. Bloos F, Reinhart K. Rapid diagnosis of sepsis. Virulence. 2014;5:154-60.

12. Dellinger RP, Levy MM, Rhodes A, et al. Surviving sepsis campaign: international guidelines for management of severe sepsis and septic shock. Intensive Care Med. 2013;39:165-228.

13. Bone RC, Balk RA, Cerra FB, et al. Definitions for sepsis and organ failure and guidelines for the use of innovative therapies in sepsis. The ACCP/SCCM consensus conference committee. American College of Chest Physicians/ Society of Critical Care Medicine. Chest. 1992;101:1644-55.

14. Herzum I, Renz H. Inflammatory indicators in SIRS, sepsis and septic shock. Curr Med Chem. 2008;15:581-7.

15. Bozza FA, Salluh Jl, Japiassu AM, et al. Cytokine profiles as indicators of disease severity in sepsis: a multiplex analysis. Crit Care. 2007;11:R49.

16. O'Shea TM, Shah B, Allred EN, et al. Inflammation-initiating illnesses, inflammation-related proteins, and cognitive impairment in extremely preterm infants. Brain Behav Immun. 2013;29:104-12.

17. Biron BM, Ayala A, Lomas-Neira JL. Biomarkers for sepsis: what is and what might be? Biomark Insights. 2015;10:7-17.

18. Khakpour S, Wilhelmsen $\mathrm{K}$, Hellman J. Vascular endothelial cell toll-like receptor pathways in sepsis. Innate Immun. 2015;21:744-8.

19. Shum HP, Yan WW, Chan TM. Recent knowledge on the pathophysiology of septic acute kidney injury: a narrative review. J Crit Care. 2016;31:82-9.

20. Ugarte $H$, Silva $E$, Mercan $D$, et al. Procalcitonin used as a marker of infection in the intensive care unit. Crit Care Med. 1999;27:498-504.

21. Ruokonen $\mathrm{E}$, Nousiainen T, Pulkki $\mathrm{K}$, et al. Procalcitonin concentrations in patients with neutropenic fever. Eur J Clin Microbiol Infect Dis. 1999;18:283-5.

22. Matthaiou DK, Ntani G, Kontogiorgi M, et al. An ESICM systematic review and meta-analysis of procalcitoninguided antibiotic therapy algorithms in adult critically ill patients. Intensive Care Med. 2012;38:940-9.

23. Wacker C, Prkno A, Brunkhorst FM, et al. Procalcitonin as a diagnostic indicator for sepsis: a systematic review and meta-analysis. Lancet Infect Dis. 2013;13:426-35.

24. Pierrakos C, Vincent JL. Sepsis biomarkers: a review. Crit Care. 2010;14:R15. 
25. Gustafsson A, Ljunggren $L$, Bodelsson $M$, et al. The prognostic value of suPAR compared to other inflammatory indicators in patients with severe sepsis. Biomark Insights. 2012:739-44. https://doi.org/10.4137/BMI.S9460.

26. Gumus A, Altintas N, Cinarka H, et al. Soluble urokinase-type plasminogen activator receptor is a novel biomarker predicting acute exacerbation in COPD. Int J Chron Obstruct Pulmon Dis. 2015;10:357-65.

27. Huttunen R, Syrjanen J, Vuento R, et al. Plasma level of soluble urokinase-type plasminogen activator receptor as a predictor of disease severity and case fatality in patients with bacteraemia: a prospective cohort study. J Intern Med. 2011;270:32-40.

28. Yilmaz G, Koksal I, Karahan SC, et al. The diagnostic and prognostic significance of soluble urokinase plasminogen activator receptor in systemic inflammatory response syndrome. Clin Biochem. 2011;44:1227-30.

29. Molkanen $\mathrm{T}$, Ruotsalainen $\mathrm{E}$, Thorball CW, et al. Elevated soluble urokinase plasminogen activator receptor (suPAR) predicts mortality in Staphylococcus aureus - bacteremia. Eur J Clin Microbiol Infect Dis. 2011;30:14-24.

30. Ostrowski SR, Plomgaard P, Fischer CP, et al. Interleukin-6 infusion during human endotoxaemia inhibits in vitro release of the urokinase receptor from peripheral blood mononuclear cells. Scand J Immunol. 2005;61:197-206.

31. Zeng $M$, Chang $M$, Zheng $H$, et al. Clinical value of soluble urokinase-type plasminogen activator receptor in the diagnosis, prognosis, and therapeutic guidance of sepsis. Am J Emerg Med. 2016;34:375-80.

32. Chen MH, Kan HT, Liu CY, et al. Serum decoy receptor 3 is a biomarker for disease severity in nonatopic asthma patients. J Formos Med Assoc. 2017;116:49-56.

33. Cheng CP, Sytwu HK, Chang DM. Decoy receptor 3 attenuates collagen-induced arthritis by modulating $T$ cell activation and B cell expansion. J Rheumatol. 2011;38:2522-35.

34. Liang $D$, Hou $Y$, Lou $X$, et al. Decoy receptor 3 improves survival in experimental sepsis by suppressing the inflammatory response and lymphocyte apoptosis. PLoS One. 2015;e0131680:10.

35. Chang YC, Chen TC, Lee CT, et al. Epigenetic control of MHC class II expression in tumor-associated macrophages by decoy receptor 3. Blood. 2008;1111:5054-63.

36. Liqin G, Bin Y, Hairong Z, et al. DcR3, a new biomarker for sepsis, correlates with infection severity and procalcitonin. Oncotarget. 2018;9:10934-44.

Ready to submit your research? Choose BMC and benefit from:

- fast, convenient online submission

- thorough peer review by experienced researchers in your field

- rapid publication on acceptance

- support for research data, including large and complex data types

- gold Open Access which fosters wider collaboration and increased citations

- maximum visibility for your research: over $100 \mathrm{M}$ website views per year 